\title{
Migration and Sexual Health Services Use - Results from the German Health and Sexuality Survey (GeSiD)
}

\author{
Christian Wiessner ${ }^{1,2}$ (D) Olaf von dem Knesebeck ${ }^{3} \cdot$ Miriam G. Gerlich $^{4} \cdot$ Peer Briken ${ }^{2} \cdot$ Heiko Becher $^{1}$
}

Accepted: 14 January 2022 / Published online: 26 January 2022

(c) The Author(s) 2022

\begin{abstract}
Introduction Migration background is an important predisposing characteristic of health service use (HSU). In this cross-sectional survey, we aim to explore the association between migration background and HSU in the context of sexual health.

Methods In a population-representative sample of 4,955 persons from all German federal states (data collection 2018/2019), we examined the HSU of first-generation (15.9\% of the total sample) and second-generation migrants (9.8\%) compared to non-migrants $(74.3 \%)$. Outcomes of sexual HSU ranged from primary and secondary prevention measures such as human papillomaviruses (HPV) vaccination and chlamydia test to HSU due to sexual problems in the relationship, and consultations on contraceptives, and HIV or other STIs.

Results Generally, first-generation migrants used sexual health services less often than non-migrants. Notably, firstgeneration migrant women had lower odds of being vaccinated against HPV (OR $=0.24 ; 95 \%$ CI: $0.14 ; 0.38)$, of a lifetime use of both a chlamydia test in the context of a screening program for young women $(\mathrm{OR}=0.21 ; 95 \% \mathrm{CI}$ : $0.11 ; 0.39$ ), and a HSU due to contraceptives ( $\mathrm{OR}=0.40 ; 95 \% \mathrm{CI}: 0.28 ; 0.58)$. Second-generation migrants resembled more closely the non-migrants, only showing differences regarding the use of the HPV vaccination $(\mathrm{OR}=0.48 ; 95 \%$ CI: $0.30 ; 0.76)$.

Policy Implications First-generation migrants showed remarkable differences in the HSU compared to non-migrants. Therefore, this group should be targeted with the aim of a more equitable HSU that is mainly based on the needs for health services and not restricted due to formal or informal barriers. Both migration generations had lower odds of being vaccinated against HPV indicating the need for a better education regarding the benefits and risks of vaccinations.
\end{abstract}

Keywords Health service use $\cdot$ HPV vaccination $\cdot$ Chlamydia test $\cdot$ Contraceptives $\cdot$ Migration $\cdot$ Generational cohorts approach $\cdot$ Native population

\section{Introduction}

Peer Briken and Heiko Becher are joint last authors.

Christian Wiessner

c.wiessner@uke.de

1 Institute of Medical Biometry and Epidemiology, University Medical Center Hamburg-Eppendorf, Martinistr. 52, 20246 Hamburg, Germany

2 Institute of Sex Research, Sexual Medicine and Forensic Psychiatry, University Medical Center Hamburg-Eppendorf, Hamburg, Germany

3 Institute of Medical Sociology, University Medical Center Hamburg Eppendorf, Hamburg, Germany

4 Federal Centre for Health Education, Cologne, Germany
Globally, 3.5\% (272 million people) of the world population are international migrants (United Nations, 2020a). In Germany, persons with a migration background are a large and increasing group as well. In the past decade, their share of the total population rose from $18.8 \%$ to $26.0 \%$ (Statistisches Bundesamt, 2020). However, migrants are a highly diverse group. This diversity is among others reflected in different countries of origin from various cultural backgrounds, the reasons for migration, the time since arrival in the host country, and their education (Kao, 2009; Rechel et al., 2013; Wiessner et al., 2020). One way to operationalize the diversity in migrant populations is to distinguish 
between first- and second-generation migrants (Glaesmer et al., 2011). First-generation migrants have an own migration experience, while second-generation migrants are descendants of persons who migrated. Previous comparisons between first- and second-generation migrants and the native population investigated different outcomes, such as education, earnings, employment (Algan et al., 2010), and health service use (Glaesmer et al., 2011), but as far as we know not sexual health.

\section{Health Service Use of Migrants}

Health service use (HSU) is a complex behavior that is influenced by many factors, migration status being one of them. Several systematic reviews found that migrants differ in their HSU compared to the native population with an overall tendency to lower utilization proportions among migrants (Norredam et al., 2010; Uiters et al., 2009; Sarría-Santamera et al., 2016; Klein \& von dem Knesebeck, 2018). However, the utilization patterns depend on the specific health services under investigation, the classification of migrants, and the country where the study is conducted. In Germany, firstgeneration migrants used the services of medical specialists, and preventive measures such as cancer screening less often, whereas second-generation migrants showed utilization behaviors that were more similar to the native population (Glaesmer et al., 2011; Rommel et al., 2015; Wiessner et al., 2020). Notably, there is a growing awareness that no general pattern regarding HSU of migrants can be observed and, thus, scientific investigations have to be seen in the light of the context of the health system of a country, and the migrant groups as well as the specific health services under investigation (Uiters et al., 2009).

The HSU in the sexual health context is less thoroughly investigated than e.g. the use of primary care among migrants. Migrant populations in Canada and Germany were found to have lower vaccination proportions against human papillomaviruses (HPV), and have a lower awareness towards the HPV immunization compared to the native population (Remschmidt et al., 2014; Sadry et al., 2013). In the Netherlands, migrants were later diagnosed with HIV, and had a higher likelihood of experiencing difficulties in the use of general healthcare services as well as a lower awareness towards post-exposure prophylaxis than non-migrants (Bil et al., 2019). A lower knowledge about different sexually transmitted infections (STIs) was also found in 9th grade school children with a migration background in a sample in Germany compared to non-migrant children (von Rosen et al., 2018). A recent systematic review found that migrants from South East Asia and Sub-Saharan Africa faced multiple barriers in high-income countries regarding the access to health care services related to sexual health (Rade et al.,
2018). These barriers included a low knowledge about the health care system and a resulting difficulty to navigate in it, feelings of stigma, shame and embarrassment to talk about sexual health, and a lacking cultural competency of health care providers.

\section{Andersen Model of Health Service Use}

The knowledge about the health care system is one factor that influences the HSU. Further factors are incorporated into Andersen's behavioral model of health service use that is most commonly used in this context, and which will be the conceptual model for our analyses (Andersen, 2008; Babitsch et al., 2012). In this model, HSU is influenced by three groups of factors: "predisposing characteristics," "enabling resources," and "need factors." Predisposing characteristics describe the observation that persons differ in their propensity to use health services based on their demographics, health beliefs, and social structure. Thus, migration status is a predisposing characteristic. Enabling resources are those factors that allow people to use health services, such as the financial ability, an existing health insurance, or the availability of health services in proximity to the living place. Need factors are those factors that directly influence the HSU due to illness, the wish for prevention, or other counseling needs. In this paper we differentiate between need factors that influence HSU as a predictor, and additionally we investigate if migration status is a predictor for unmet needs, i.e., where participants stated a wish for the use of health services, but did not consult a medical professional.

\section{Current Study - Aim and Hypotheses}

In this study, we aim to investigate if migration status is associated with the HSU. Additionally, we study the relationship between migration status and unmet needs of health services, the knowledge of specific preventive measures, and the satisfaction with consultations. The health services under investigation are consultations due to sexual problems, and the use of the primary and secondary preventive measures of a HPV vaccination, and a chlamydia test. With both the HPV vaccination and the chlamydia test, we aimed to investigate unfulfilled potentials to avoid STIs through a use of health services that is aligned with the effort to limit the spread of these STIs. Thereby, both personal and public health may be improved. Moreover, we examine the use of health services in which participants either stated that they communicated with a physician or wish to communicate with a physician due to sexual problems in the relationship, HIV or other STIs, and contraceptives. An unfulfilled wish to communicate with a medical professional is conceptualized as an unmet need. Finally, we compare the migration generations with non-migrants regarding the knowledge about the 
preventive measures of a HPV vaccination and a chlamydia test, and the satisfaction with consultations concerning sexual problems. For the sexual problems, we further explore the reasons not to use health services, although a problem was experienced. Generally, we hypothesized that first-generation migrants differ in the various dimensions compared to nonmigrants, while we expected that the knowledge and HSU from second-generation migrants resembled more closely the one observed for non-migrants.

\section{Methods}

\section{Study Design and Sample}

The data analyzed stem from the German Health and Sexuality Survey (GeSiD), a cross-sectional study with a populationrepresentative sampling scheme (Matthiesen et al., 2021). Two hundred sample points from all German federal states were randomly chosen, from which 18 - to 75 -year-old participants were randomly sampled. The data collection took place from October 2018 to September 2019, and the final dataset comprised 4,955 persons, which corresponded to a response proportion of $30.2 \%$ (Response Proportion 4 according to: American Association for Public Opinion Research, 2016). All persons living in private households were eligible to be included in the study; only persons living in an institution were excluded by study design.

Trained interviewers conducted interviews in the participant's homes. Prior to the interviewer's visit, the sampled participants received an invitation letter with brief information about the study. The data were acquired by a computerassisted personal interview (CAPI), and a computer-assisted self-interview (CASI). In the CAPI part, general sociodemographic questions were asked, while the CASI part contained the more sensitive questions. The questionnaire was pretested in a pilot study among 1,555 participants and comprised 263 questions in German language (Matthiesen et al., 2018). Average time for an interview was 51 minutes. The GeSiD study received approval from the Ethical Board of the State Psychotherapy Chamber in Hamburg (reference: 07/2018-PTK-HH). A detailed description of the methodology of the GeSiD study can be found in Matthiesen et al. (2021).

\section{Conceptual Model}

A conceptual model on the basis of Andersen's behavioral model of health service use was developed that categorized the predictors into enabling resources, need factors, and predisposing characteristics. The migration background is a predisposing characteristic, while further factors that influence HSU were included into the analyses as covariates (gender, age, education, and relationship status as predisposing characteristics, urban/rural residence as an enabling resource, and general health status as a need factor). Outcomes were classified into knowledge about the health care system, HSU (differentiated into either consultations due to a specific medical reason, or the communication about an issue during a medical visit), unmet needs, and satisfaction with health services used (Table 1). We were interested not only in the knowledge about the health care system, HSU, and satisfaction with HSU as outcomes, but also whether migrants differ in their unmet needs for sexual health services from non-migrants. Therefore, we included unmet needs as outcomes in our analyses, which is a slight deviation from the Andersen model as it is commonly used.

\section{Measures of Predictors}

Migration Background as a Predisposing Characteristic The migration background was assigned in accordance with the definition of the German Statistical Office (Statistisches Bundesamt, 2018). A person has a migration background,

Table 1 Conceptual model of health behavior on the basis of Andersen's model of health service use

\begin{tabular}{|c|c|c|c|c|}
\hline \multicolumn{5}{|l|}{ Predictors } \\
\hline Predisposing characteristics & Enabling resources & Need factors & & \\
\hline $\begin{array}{l}\text { Migration background } \\
\text { Gender } \\
\text { Age } \\
\text { Education } \\
\text { Relationship status }\end{array}$ & Urban/rural residence & General health status & & \\
\hline \multicolumn{5}{|l|}{ Outcomes } \\
\hline Knowledge & Health service use: Consultation & $\begin{array}{l}\text { Health service use: } \\
\text { Communication }\end{array}$ & Unmet needs & Satisfaction \\
\hline $\begin{array}{l}\text { HPV vaccination } \\
\text { Chlamydia test }\end{array}$ & $\begin{array}{l}\text { HPV vaccination } \\
\text { Chlamydia test } \\
\text { Sexual problems }\end{array}$ & $\begin{array}{l}\text { Sexual problems in relationship } \\
\text { HIV or other STIs } \\
\text { Contraceptives }\end{array}$ & $\begin{array}{l}\text { Sexual problems in } \\
\text { relationship } \\
\text { HIV or other STIs } \\
\text { Contraceptives }\end{array}$ & $\begin{array}{l}\text { Satisfaction with consultation } \\
\text { due to sexual problems }\end{array}$ \\
\hline
\end{tabular}


if the person itself or at least one parent did not have the German citizenship at birth. Questions about the birth country of the participant and her/his parents, and the current citizenship(s) of the participant and her/his parents' citizenship at birth were used to evaluate the migration status. Participants with a migration background who were born in Germany are considered second-generation migrants, while those with an own migration experience are subsequently termed first-generation migrants. For 4,931 of 4,955 participants, the migration status could be obtained, while 24 participants did not provide sufficient information for classification and were thus excluded from further analyses.

Further Predisposing Characteristics Education was categorized into low (no completed school or primary education), medium (secondary education), and high (tertiary education). Relationship status was a binary measure indicating whether participants were in a relationship or not. Age was treated as a continuous variable, and sex as a binary variable using the information from the registry office.

Enabling Resources The residence of participants was obtained by registry data, and dichotomized into rural (living in a settlement of up to 5,000 inhabitants) and urban (living in a settlement of more than 5,000 inhabitants).

Need Factors General health status was measured as one item on a 5-point scale ranging from very good to very poor.

\section{Outcome Measures}

Knowledge About Health Services The survey asked women about their awareness of two preventive measures, vaccination against HPV between the ages of 9 and 14 years, and a yearly free-of-charge chlamydia test (screening) for young women as secondary prevention which is offered for sexually active women under 25 years in Germany.

\section{Health Service Use: Consultation}

For the HPV vaccination and the chlamydia test, those women who knew these preventive measures were asked if they were vaccinated against HPV/ever were tested for chlamydia in the context of the screening program. Women aged between 18 and 35 were questioned, because both preventive measures were only recommended since 2007 (HPV vaccination, Robert Koch-Institut, 2007), respectively 2008 (Chlamydia screening program, Gemeinsamer Bundesausschuss, 2008), and incorporated into the free-of-charge offer of German insurance companies. Moreover, all participants were asked if they had sought professional advice and support in the past 5 years due to any sexual problem. Sexual problems under consideration were a reduced sexual desire, problems to reach an orgasm, reduced reactions to sexual stimuli (only women), pain during sex (only women), premature ejaculation (only men), and problems to get an erection (only men) (Briken et al., 2020).

\section{Health Service Use: Communication and Unmet Needs}

Participants were further asked if they ever talked to a physician or had the wish to talk to a physician about the following three topics:

- Sexual problems in the relationship

- HIV/AIDS or other STIs

- Contraceptives

The questions had three possible answers, "Yes, I talked to a physician," "No, but I would like to," and "No, and I don't want to." Those participants who stated that they did not talk to a physician but would like to were regarded to have an unmet need.

\section{Satisfaction with Services Used}

For the health service use due to sexual problems, the participants who visited a medical professional were questioned about their satisfaction with the consultation. Satisfaction was measured on a 5-point scale ranging from very satisfied to very dissatisfied. This scale was dichotomized into high degree of satisfaction (very satisfied, quite satisfied) vs. low degree of satisfaction (neither satisfied nor dissatisfied, quite dissatisfied, very dissatisfied).

\section{Reasons Not to Use Health Service Despite a Perceived Need}

Participants who had a need for health services due to sexual problems, but did not consult a medical professional were asked about the reasons why they did not seek for help. Eleven options were given that were e.g. related to shame ("I found it embarrassing," "I didn't want others to know about my problem"), language problems ("I couldn't talk about my problem"), preferences of the partner ("My partner didn't approve"), and the services in the community ("There were no such services offered where I live," "The waiting periods were too long").

\section{Statistical Analysis}

In the GeSiD study, the selection of participants was carried out as a stratified and clustered random sample. Due to varying response proportions in different population groups (by sex, age, education, nationality, and region) and an oversampling of young participants (18-35 years), a weighting was 
applied in order to get a representative sample of the German population in the age range 18 to 75 years. Therefore, a survey data analysis was carried out that accounted for the strata, cluster, and weights. In a first step, a crude analysis of the proportions for the different outcomes was conducted that was stratified by migration status. Then, multiple logistic regressions were employed. All regression models included migration background as the main predisposing characteristic of interest, and adjusted for gender, age, education, relationship status, urban/rural residence, and general health status. The following outcomes were binary and thus analyzed via binary logistic regression:

- Knowledge (HPV vaccination, and chlamydia test)

- Health service use: consultation (HPV vaccination, chlamydia test, sexual problems)

- Satisfaction with consultation due to sexual problems

The outcomes related to "Health service use: communication" and "Unmet needs" had three independent categories, and were therefore assessed via multinomial logistic regression. These were the questions related to sexual problems in a relationship, HIV/AIDS or other STIs, and contraceptives. The communication with a physician and unmet needs in these topics were compared to the category "both no use and no need" as the reference category.

For all outcomes, we report adjusted odds ratios (aOR) with the corresponding 95\% confidence interval (CI). Firstand second-generation migrants were compared to nonmigrants as the reference category. Interactions between gender and migration status were assessed via significance of the regression coefficient (significance level $\alpha=0.05$ ). If an interaction was present, the model was stratified by gender. A complete case analysis was conducted, because for all regression models less than 5\% of eligible participants were lost due to missing values.

Additionally, cross tabulations were computed between migration status and the reasons not to use health services regarding sexual problems. Cross tabulations for categorical variables were compared by the chi-square test for survey samples (the Rao-Scott test, Rao \& Scott, 1981). All analyses were conducted with SAS software version 9.4 (SAS Institute, Cary, NC); for figures the ggplot2 package of the statistical software R was used.

\section{Results}

Among 4,931 participants where we could assign a migration status, 636 (12.9\%) were first-generation migrants, and 484 (9.8\%) second-generation migrants (Table 2). First- and second-generation migrants were in comparison to non-migrants on average younger, had more often a low education, and a better general health status. However, there were no differences in the general health status after adjustment for age (not shown in detail). Additionally, firstgeneration migrants were more often highly educated compared to non-migrants, while there were no sex differences between the three groups. The most common foreign birth countries of migrants were Poland $(n=76)$, Russia $(n=62)$, Kazakhstan $(n=43)$, Turkey $(n=40)$, and Syria $(n=30)$. Three out of four second-generation migrants and 1 out of 5 first-generation migrants had German as their mother language (Table 3). While the majority of first-generation migrants $(93.3 \%)$ had a two-sided migration background,

Table 2 Sociodemographic characteristics

\begin{tabular}{|c|c|c|c|c|}
\hline & $\begin{array}{l}\text { Persons without migration background } \\
\text { (unweighted } N=3811 \text {, weighted } \\
N=3660 \text { ) }\end{array}$ & $\begin{array}{l}\text { Persons with migration } \\
\text { background (1st generation) } \\
\text { (unweighted } N=636 \text {, weighted } \\
N=783 \text { ) }\end{array}$ & $\begin{array}{l}\text { Persons with migration background } \\
\text { (2nd generation) (unweighted } \\
N=484 \text {, weighted } N=483 \text { ) }\end{array}$ & $p$-value \\
\hline Female gender $(\%)$ & 50.0 & 49.9 & 48.6 & 0.880 \\
\hline Age $(\operatorname{Mean}(\mathrm{SD}))$ & $48.4(15.3)$ & $41.9(15.7)$ & $37.2(14.6)$ & $<0.001$ \\
\hline In relationship (\%) & 76.8 & 75.3 & 68.9 & 0.007 \\
\hline \multicolumn{5}{|l|}{ Education $(\%)$} \\
\hline $\begin{array}{l}\text { Low } \\
\text { Medium } \\
\text { High }\end{array}$ & $\begin{array}{l}29.5 \\
35.1 \\
35.5\end{array}$ & $\begin{array}{l}38.3 \\
20.2 \\
41.5\end{array}$ & $\begin{array}{l}37.4 \\
26.5 \\
36.1\end{array}$ & $<0.001$ \\
\hline \multicolumn{5}{|c|}{ General health status (\%) } \\
\hline $\begin{array}{l}\text { Very good } \\
\text { Good } \\
\text { Average } \\
\text { Poor } \\
\text { Very poor }\end{array}$ & $\begin{array}{l}23.1 \\
52.6 \\
19.8 \\
3.6 \\
0.9\end{array}$ & $\begin{array}{l}32.4 \\
50.3 \\
13.8 \\
2.2 \\
1.4\end{array}$ & $\begin{array}{l}35.4 \\
45.7 \\
14.8 \\
3.1 \\
0.9\end{array}$ & $<0.001$ \\
\hline Urban residence (\%) & 83.7 & 93.0 & 91.7 & $<0.001$ \\
\hline
\end{tabular}


Table 3 Characteristics of the persons with migration background
Persons with migration background Persons with migration (1st generation, $N=636$ ) background (2nd generation, $N=484)$

\begin{tabular}{|c|c|c|}
\hline \multicolumn{3}{|l|}{ Place of Origin $(\%(n))$} \\
\hline $\begin{array}{l}\text { Africa } \\
\text { Asia } \\
\text { Northern/Western Europe } \\
\text { Eastern Europe } \\
\text { Southern Europe } \\
\text { Northern America } \\
\text { Middle/Southern America } \\
\text { Missing values }\end{array}$ & $\begin{array}{l}3.8(24) \\
33.9(212) \\
9.6(60) \\
39.6(248) \\
13.9(87) \\
0.6(4) \\
3.4(21) \\
(10)\end{array}$ & \\
\hline \multicolumn{3}{|l|}{ Place of origin father $(\%(n))$} \\
\hline $\begin{array}{l}\text { Africa } \\
\text { Asia } \\
\text { Northern/Western Europe } \\
\text { Eastern Europe } \\
\text { Southern Europe } \\
\text { Northern America } \\
\text { Middle/Southern America } \\
\text { Germany }\end{array}$ & & $\begin{array}{l}3.1(15) \\
22.9(111) \\
7.6(37) \\
19.8(96) \\
16.7(81) \\
1.0(5) \\
1.7(8) \\
27.1(131)\end{array}$ \\
\hline $\begin{array}{l}\text { Place of origin mother }(\%(n)) \\
\text { Africa } \\
\text { Asia } \\
\text { Northern/Western Europe } \\
\text { Eastern Europe } \\
\text { Southern Europe } \\
\text { Northern America } \\
\text { Middle/Southern America } \\
\text { Germany }\end{array}$ & & $\begin{array}{l}1.7(8) \\
21.7(105) \\
7.4(36) \\
20.9(101) \\
13.0(63) \\
0.8(4) \\
1.2(6) \\
33.3(161)\end{array}$ \\
\hline $\begin{array}{l}\text { German mother language }(\%) \\
\text { Yes } \\
\text { Missing values }\end{array}$ & $\begin{array}{l}19.5(123) \\
(5)\end{array}$ & $\begin{array}{l}75.6(365) \\
(1)\end{array}$ \\
\hline \multicolumn{3}{|c|}{$\begin{array}{l}\text { One-sided/two-sided migration back- } \\
\text { ground }(\%(n))\end{array}$} \\
\hline $\begin{array}{l}\text { One-sided } \\
\text { Two-sided } \\
\text { Missing values }\end{array}$ & $\begin{array}{l}6.9(36) \\
93.1(488) \\
(112)\end{array}$ & $\begin{array}{l}55.3(259) \\
44.7(209) \\
(16)\end{array}$ \\
\hline
\end{tabular}

second-generation migrants more often had a one-sided migration history of their parents $(55.3 \%)$.

Results from crude analyses (proportions stratified by migration status) as well as the multiple regression models (adjusted odds ratios (aOR)) are depicted in Fig. 1. Generally, first-generation migrants differed in various dimensions compared to non-migrants, while second-generation migrants resembled more closely the non-migrant population. Firstgeneration migrant women were less aware of the preventive measures HPV vaccination $(\mathrm{aOR}=0.23,95 \% \mathrm{CI} 0.17-0.31)$ and chlamydia test $(\mathrm{aOR}=0.35,95 \% \mathrm{CI} 0.24-0.50)$ than nonmigrant women, while second-generation migrant women were in between these numbers.

The utilization of the two preventive measures HPV vaccination and the chlamydia test differed between the migration generations, and non-migrants. While almost half of the non-migrant women between 18 and 35 years got a vaccination (47.0\%), only about one-third of the second-generation migrant women $(35.1 \%, \mathrm{aOR}=0.48$, 95\% CI $0.30-0.76)$ and 1 out of 7 of the first-generation women $(15.3 \%, \mathrm{aOR}=0.24,95 \%$ CI $0.14-0.38)$ used the HPV vaccination. Similarly, non-migrant women used the free-of-charge chlamydia test most often $(23.0 \%)$, followed by second- $(17.1 \%$, aOR $=0.73,95 \%$ CI $0.42-1.27)$ and first-generation migrant women $(5.2 \%, \mathrm{aOR}=0.21,95 \%$ CI 0.11-0.39). The HSU due to sexual problems showed small differences between the three groups; first-generation migrants consulted a medical professional with the lowest probability $(\mathrm{aOR}=0.65,95 \%$ CI 0.39-1.09).

The outcomes related to the communication with a medical professional or the unfulfilled wish to talk to a doctor (unmet needs) about a specific issue differed between both migration generations and non-migrants. First- and second-generation migrants reported higher unmet needs for professional 


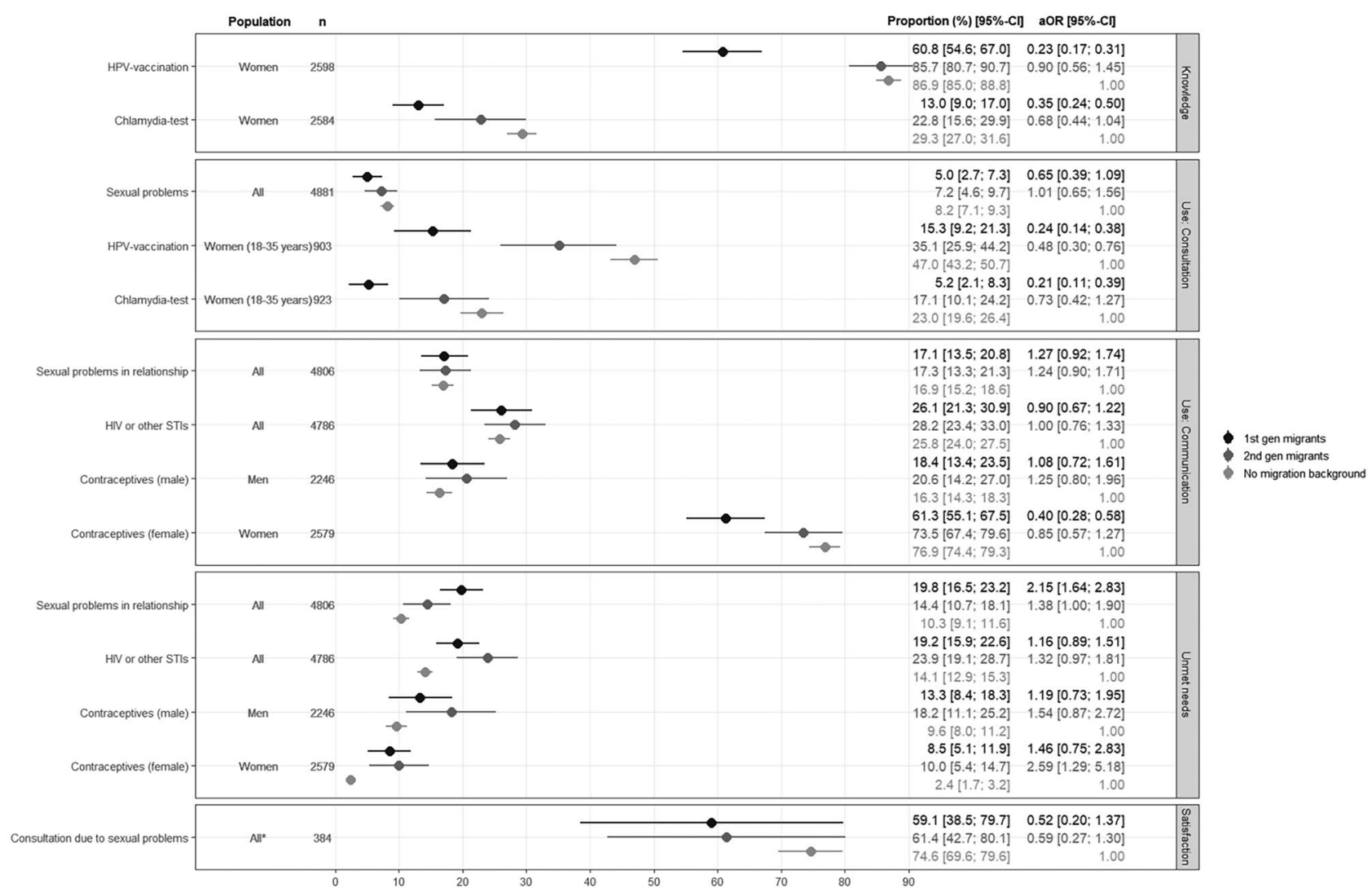

Fig. 1 Knowledge about preventive measures, need factors, use of health services, and satisfaction with a professional consultation due to sexual problems stratified by migration status, and odds ratios from multiple logistic regression models comparing first- and second-generation migrants to persons without a migration background. Odds ratios with
95\% confidence intervals $[95 \% \mathrm{CI}]$ are adjusted for gender, age, education, relationship status, urban/rural residence, and general health status. First-gen migrants: persons with a migration background and an own migration experience. Second-gen migrants: persons with a migration background that were born in Germany consultations than non-migrants. First-generation migrants experienced comparatively high unmet needs for HSU concerning sexual problems in the relationship $(\mathrm{aOR}=2.15,95 \% \mathrm{CI}$ 1.64-2.83), while second-generation migrants had comparatively high unmet needs for a HSU concerning contraceptives (female: $\mathrm{aOR}=2.59,95 \%$ CI 1.29-5.18, male: $\mathrm{aOR}=1.54,95 \%$ CI 0.87-2.72). Communication about sexual problems, HIV, or other STIs and contraceptives was similar for the two migration generations and non-migrants. However, first-generation women spoke about contraceptives less frequently $(\mathrm{aOR}=0.40$, 95\% CI 0.28-0.58) than second-generation women and the nonmigrant women.

Satisfaction with consultations in the subpopulation of persons seeking medical advice for sexual problems differed between migrants and non-migrants. Both first(59.1\% satisfied, aOR $=0.52,95 \%$ CI $0.20-1.37)$ and second-generation migrants $(61.4 \%$ satisfied, $\mathrm{aOR}=0.59$, 95\% CI 0.27-1.30) were less satisfied with the consultations compared to non-migrants ( $74.6 \%$ satisfied).
The reasons not to use health services regarding sexual problems differed between non-migrants and the two migration generations (Fig. 2). Significant differences were found for the following reasons:

- "I couldn't talk about my problem" (17.9\% first-generation migrants, $12.1 \%$ second-generation migrants, $8.6 \%$ nonmigrants respectively)

- "I didn't want others to know about my problem" $(11.6 \%, 5.7 \%, 5.6 \%)$

- "I found it embarrassing" (19.7\%, 15.6\%, 13.6\%)

- "My partner didn't approve" (4.2\%, 3.4\%, 1.2\%)

- "I assumed that the problem would sort itself out" $(20.8 \%, 27.9 \%, 27.7)$

First-generation migrants reported reasons related to shame, language problems, and partner approval more often than non-migrants, while they expected it less often that the problem would settle without professional help. 
Fig. 2 Reasons not to seek professional advice despite a perceived need for a consultation due to sexual problems stratified by migration status. Answers marked with an asterisk $(*)$ differ significantly between at least two groups indicated by the chisquare test for survey samples (Rao-Scott test)

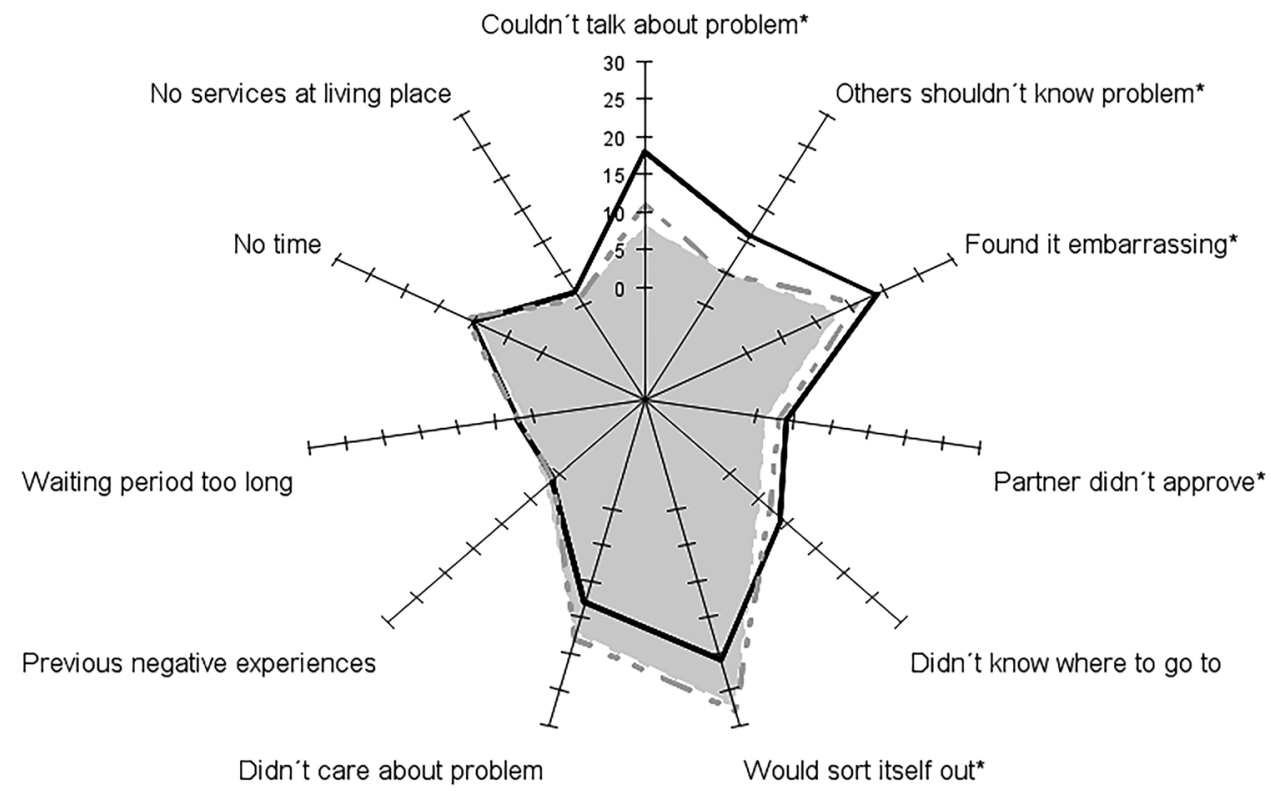

No migration background $\square$ First generation migrants $\square$ Second generation migrants

\section{Discussion}

Our aim was to compare first- and second-generation migrants with non-migrants regarding sexual HSU, knowledge about health services, unmet needs, and satisfaction with HSU in a population-representative study. Generally, first-generation migrants differed in many dimensions from the non-migrants. In contrast, non-migrants and second-generation migrants showed a more similar behavior regarding many of the outcomes. The only HSU where both migration generations differed significantly from non-migrants was the HPV vaccination. While first-generation migrant women $(60.8 \%)$ had a lower knowledge about the existence of this primary prevention measure, second-generation migrant women $(85.7 \%)$ and native-born German women $(86.9 \%)$ did not differ in their awareness. Thus, the differences in the vaccination proportions between these two groups cannot be explained by the knowledge about the existence of this prevention measure. Additionally, the chlamydia test and HSU concerning contraceptives (in the female population) were less often used by first-generation migrants compared to non-migrants, and second-generation migrants. The differences in HSU between first- and second-generation migrants show the necessity to take into account the heterogeneity of migrant populations, an argument brought up by other authors as well (Norredam et al., 2010; Rechel et al., 2013).

\section{Migration Status}

The identification and classification of migrants in the HSU literature is as diverse as the migration population itself.
Migration status is identified by varying combinations of characteristics like nationality, country of birth, ethnicity/race, mother language, and self-identification (Uiters et al., 2009). Classifications may be done by specific regions/countries of origin (e.g., Lagerlund et al., 2002), one- or two-sided migration background (e.g., Brzoska \& Abdul-Rida, 2016), time since arrival (e.g., Rivera et al., 2015), acculturation assessment (e.g., Mikolajczyk et al., 2008), and migration generation (e.g., Glaesmer et al., 2011). Still, often a simple binary categorization "migrants vs. non-migrants" is used (e.g., Knopf et al., 2012). We identified the participants' migration status by their own and their parents' nationality at birth and their birth country. Subsequently, we classified migrants by their generation; i.e., we differentiated between migrants who were born abroad (first-generation migrants), and persons who were born in Germany, while their parents had a migration experience (second-generation migrants). The differences that we found between first- and second-generation migrants corroborate the need to take the diversity of migrant populations into account. In a previous work (Wiessner et al., 2020), we investigated the use of colorectal cancer screening in a large cohort study, and found that the migration generation was the characteristic explaining the largest part of the difference in HSU between migrants and non-migrants. Glaesmer et al. (2011) came to similar conclusions investigating the HSU of general practitioners and medical specialists.

\section{Health Service Use in the Context of Sexuality}

In this paper, we explored the communication with a physician about sexual problems in the relationship, HIV or other 
STIs, and contraceptives. We further investigated the HSU regarding consultations due to sexual problems, a chlamydia test in the context of a screening program, and a HPV vaccination. Notably, Remschmidt et al. (2014) found a similar association between migration background and HPV vaccine uptake in a sample of women between 20 and 25 years from Germany. In a Canadian study, a positive association between the knowledge about the HPV vaccination and an interest to be vaccinated was found in a population of Caucasian and non-Caucasian women (Sadry et al., 2013). In contrast, our results revealed that second-generation migrants in Germany had a similar knowledge about the HPV vaccination compared to non-migrants, but had a substantial lower HPV vaccine uptake. For the remaining health services under investigation, no significant differences between second-generation migrants and non-migrants were found, albeit there were tendencies towards a lower awareness about the possibility to be tested for chlamydia, and the actual HSU of a chlamydia test. However, second-generation migrants showed higher unmet needs regarding HSU. Particularly, second-generation migrants had high unmet needs concerning the communication with a physician about contraceptives. This finding is in accordance with the literature, where unmet needs for a HSU concerning contraceptive advice in migrant population were found in different countries and migrant populations (Allotey et al., 2004; Aptekman et al., 2014; Ellawela et al., 2017; Gele et al., 2019). Globally, nearly 200 million women in the reproductive age have an unmet need for the use of contraceptives, which, as a result, leads to mistimed or unwanted pregnancies that contribute to high rates of abortions (United Nations, 2020b). By addressing the unmet needs for health services concerning contraceptives, these unwanted effects may be reduced in migrant populations. Markedly, both migration generations had comparatively high unmet needs for all outcomes in our analysis. First-generation migrants reported particularly high unmet needs for health services regarding sexual problems in the relationship. Medical professionals should be aware that 1 out of 5 first-generation migrants have unmet needs to communicate about sexual problems in the relationship.

We further investigated the satisfaction with the HSU. Both migration generations were less satisfied with consultations due to sexual problems compared to non-migrants. However, the number of persons who consulted a physician due to sexual problems was small $(n=384)$, and the results were not significant. Yet, only $59.1 \%$ of the first-generation migrants, and $61.4 \%$ of the second-generation migrants were satisfied with the consultations compared to $74.6 \%$ of the non-migrants. Therefore, the satisfaction with sexual HSU in migrant populations is a topic for further research, ideally in larger samples than ours. In a recent German study, parents with a migration background were less satisfied with the ambulant health care provision for their children compared to parents without a migration background (Frank et al., 2020).

\section{Access and Barriers to Health Service Use}

Formal and informal barriers restrict the access to health services. Formal barriers for HSU of migrants are considered to be legal entitlements, not having a health insurance, and costs for services (Rechel et al., 2013). These barriers are greatest for asylum seekers and undocumented migrants. In our sample of participants living in private homes, the more informal barriers were hypothesized to be the greater source of variability in HSU between migrants and non-migrants. These include language problems, problems to navigate in the health system, inadequate health literacy, social exclusion, and discrimination (Rechel et al., 2013). In our study, we investigated the reasons not to use health services due to sexual problems, although a need was perceived. While second-generation migrants and non-migrants did not differ significantly in their motives for no HSU, first-generation migrants showed differences. Informal barriers played an important role not to consult a physician. Reasons related to shame ("I didn't want others to know about my problem," "I found it embarrassing") and language problems ("I couldn't talk about my problem") were more frequently mentioned by first-generation migrants compared to the other two groups. In contrast, first-generation migrants less frequently expected that the problem would sort itself out without professional support compared to both second-generation migrants and non-migrants. Markedly, formal barriers did not play a role for no HSU; the access to services was comparable between the three groups. No services at the living place and too long waiting periods were mentioned by few participants from both migration generations and non-migrants.

\section{Strengths and Limitations}

Our study was the first to investigate different outcomes of sexual HSU in a large German sample. The data in our study were obtained by population-representative sampling, and persons with a migration background (unweighted: $22.7 \%$, weighted: $25.7 \%$ ) were represented similar to the general population $(26.0 \%$, Statistisches Bundesamt, 2020). Additionally, we asked about different dimensions of HSU; thereby we obtained a comprehensive view of the HSU in the sexual health context of migrants and non-migrants in Germany. However, we also need to mention some limitations. Firstly, we classified migrants by their migration generation, and ignored further heterogeneity arising e.g. from different countries/regions of origin, cultural and religious backgrounds, and the time since arrival. The time since arrival was not assessed in our survey, but would have been an important information 
especially for the HSU of the HPV vaccination (recommended for girls between the ages of 9 and 14 years), and the chlamydia test (offered once a year free of charge for sexually active women under 25 years as a screening program). Secondly, sufficient language skills were needed to participate in the interview. Therefore, migrants with little knowledge of the German language were not included in our survey. Thus, our results are probably biased and differences of HSU between migrants and non-migrants may be underestimated.

\section{Policy Implications and Conclusion}

Our results imply that actions should be taken to improve equity in the access to sexual health services. Potential interventions should take into account the diversity of migrant populations and be tailored towards the needs of different migrant groups (Rechel et al., 2013). The health literacy of migrants should be improved, and differences in the knowledge about health service provision and prevention measures should be minimized. Otherwise, inequalities in the utilization of medical services may potentially contribute to harmful consequences. For example, migrants from Sub-Saharan Africa and Caribbean countries living in European countries have substantially higher mortality rates due to HIV/AIDS compared to native-born populations (Ikram et al., 2016). Generally, access to health services should be guided by needs. The unmet needs in both migration generations, and the substantially lower HSU of first-generation migrations in our study are indicators that there is room for improvement towards an equitable access to and utilization of health services. Cultural competences among health care workers that may be improved in the training could reduce informal barriers of HSU. For future scientific studies, it would be interesting to investigate the migrant population in more depth, i.e., to consider regions/ countries of origin, length of stay, acculturation, religious beliefs, and their associations to HSU. Overall, our results imply that policy makers should be aware of the differences in HSU between specific migrant groups and non-migrants, and a reduction of barriers to access is necessary.

Funding Open Access funding enabled and organized by Projekt DEAL. The research leading to these results received funding from the Bundeszentrale für gesundheitliche Aufklärung (Federal Center for Health Education) under Grant [Z2/ 25.5.2.1/16] (pilot study) and Grant [Z2/25.5.2.1./18] (main study).

\section{Declarations}

Ethical Approval All procedures performed in studies involving human participants were in accordance with the ethical standards of the institutional and/or national research committee and with the 1964 Helsinki declaration and its later amendments or comparable ethical standards.
Consent to Participate Informed consent was obtained from all individual participants included in the study.

Conflict of Interest The authors declare no competing interests.

Open Access This article is licensed under a Creative Commons Attribution 4.0 International License, which permits use, sharing, adaptation, distribution and reproduction in any medium or format, as long as you give appropriate credit to the original author(s) and the source, provide a link to the Creative Commons licence, and indicate if changes were made. The images or other third party material in this article are included in the article's Creative Commons licence, unless indicated otherwise in a credit line to the material. If material is not included in the article's Creative Commons licence and your intended use is not permitted by statutory regulation or exceeds the permitted use, you will need to obtain permission directly from the copyright holder. To view a copy of this licence, visit http://creativecommons.org/licenses/by/4.0/.

\section{References}

Algan, Y., Dustmann, C., Glitz, A., \& Manning, A. (2010). The economic situation of first and second-generation immigrants in France, Germany and the United Kingdom. The Economic Journal, 120, 4-30.

Allotey, P., Manderson, L., Baho, S., \& Demian, L. (2004). Reproductive health for resettling refugee and migrant women. Health Issues, 78, 12-17.

American Association for Public Opinion Research. (2016). Standard definitions: Final dispositions of case codes and outcome rates for surveys (Report No. 9). Retrieved from: https://www.aapor.org/AAPOR Main/media/publications/Standard-Defintitions20169theditionfinal. pdf

Andersen, R. M. (2008). National health surveys and the behavioral model of health services use. Medical Care, 46(7), 647-653. https://doi.org/10.1097/MLR.0b013e31817a835d

Aptekman, M., Rashid, M., Wright, V., \& Dunn, S. (2014). Unmet contraceptive needs among refugees. Canadian Family Physician, 60(12), 613-619.

Babitsch, B., Gohl, D., \& von Lengerke, T. (2012). Re-revisiting Andersen's behavioral model of health services use: A systematic review of studies from 1998-2011. Psycho-social Medicine, 9, Doc11. https://doi.org/10.3205/psm000089

Bil, J. P., Zuure, F. R., Alvarez-Del Arco, D., Prins, J. M., Brinkman, K., Leyten, E., van Sighem, A., Burns, F., \& Prins, M. (2019). Disparities in access to and use of HIV-related health services in the Netherlands by migrant status and sexual orientation: A cross-sectional study among people recently diagnosed with HIV infection. BMC Infectious Diseases, 19(906), 1-13. https://doi. org/10.1186/s12879-019-4477-2

Briken, P., Matthiesen, S., Pietras, L., Wiessner, C., Klein, V., Reed, G. M., \& Dekker, A. (2020). Estimating the prevalence of sexual dysfunction using the new ICD-11 Guidelines. Deutsches Arzteblatt International, 117(39), 653-658. https://doi.org/10.3238/ arztebl.2020.0653

Brzoska, P., \& Abdul-Rida, C. (2016). Participation in cancer screening among female migrants and non-migrants in Germany: A cross-sectional study on the role of demographic and socioeconomic factors. Medicine, 95(30), 1-7. https://doi.org/10.1097/ MD.0000000000004242

Ellawela, Y., Nilaweera, I., Holton, S., Rowe, H., Kirkman, M., Jordan, L., McNamee, K., Bayly, C., McBain, J., Sinnott, V., \& Fisher, J. (2017). Contraceptive use and contraceptive health care needs among Sri Lankan migrants living in Australia: Findings from 
the understanding fertility management in contemporary Australia survey. Sexual \& Reproductive Healthcare, 12, 70-75.

Frank, L. K., Schenk, L., Rommel, A., Thamm, R., Ellert, U., \& Lampert, T. (2020). Inanspruchnahme ambulant ärztlicher Leistungen und Zufriedenheit mit der Versorgung bei Kindern und Jugendlichen mit Migrationshintergrund - Ergebnisse der KiGGS-Studie [Utilization of outpatient medical services and satisfaction with care in children and adolescents with a migration background-results of the KiGGS study]. Bundesgesundheitsblatt, Gesundheitsforschung, Gesundheitsschutz, 63(1), 103-112. https://doi.org/10.1007/s00103-019-03069-8

Gemeinsamer Bundesausschuss. (2008). Screening auf genitale Chlamydia trachomatis-Infektionen bei Frauen. Abschlussbericht des Unterausschusses Familienplanung des Gemeinsamen Bundesausschusses.

Glaesmer, H., Wittig, U., Braehler, E., Martin, A., Mewes, R., \& Rief, W. (2011). Health care utilization among first and second generation immigrants and native-born Germans: A population-based study in Germany. International Journal of Public Health, 56(5), 541-548. https://doi.org/10.1007/s00038-010-0205-9

Gele, A. A., Musse, F. K., \& Qureshi, S. (2019). Unmet needs for contraception: A comparative study among Somali immigrant women in Oslo and their original population in Mogadishu, Somalia. PLoS One, 14(8), e0220783. https://doi.org/10.1371/journal. pone. 0220783

Ikram, U. Z., Mackenbach, J. P., Harding, S., Rey, G., Bhopal, R. S., Regidor, E., Rosato, M., Juel, K., Stronks, K., \& Kunst, A. E. (2016). All-cause and cause-specific mortality of different migrant populations in Europe. European Journal of Epidemiology, 31(7), 655-665. https://doi.org/10.1007/s10654-015-0083-9

Kao, D. T. (2009). Generational cohorts, age at arrival, and access to health services among Asian and Latino immigrant adults. Journal of Health Care for the Poor and Underserved, 20(2), 395-414. https://doi.org/10.1353/hpu.0.0144

Klein, J., \& von dem Knesebeck, O. (2018). Inequalities in health care utilization among migrants and non-migrants in Germany: A systematic review. International Journal for Equity in Health, 17(1), 160. https://doi.org/10.1186/s12939-018-0876-z

Knopf, H., Hölling, H., Huss, M., \& Schlack, R. (2012). Prevalence, determinants and spectrum of attention-deficit hyperactivity disorder (ADHD) medication of children and adolescents in Germany: Results of the German health interview and examination survey (KiGGS). British Medical Journal Open, 2(6), e000477. https:// doi.org/10.1136/bmjopen-2011-000477

Lagerlund, M., Maxwell, A. E., Bastani, R., Thurfjell, E., Ekbom, A., \& Lambe, M. (2002). Sociodemographic predictors of non-attendance at invitational mammography screening - A population-based register study (Sweden). Cancer Causes \& Control : CCC, 13(1), 73-82. https://doi.org/10.1023/a:1013978421073

Matthiesen, S., Dekker, A., \& Briken, P. (2018). Pilot study on adult sexuality in Germany - First results on feasibility and comparison of methods. Zeitschrift Fur Sexualforschung, 31(3), 218-236. https://doi.org/10.1055/a-0663-4354

Matthiesen, S., Pietras, L., Bode, H., Cholmakow-Bodechtel, C., Cerwenka, S., Pfister, M., von Rüden, U., Steinacker, G., Wiessner, C., Briken, P., \& Dekker, A. (2021). Methodology of the German national sex survey - GeSiD (German health and sexuality survey). Journal of Sex Research, 58(8), 1008-1018. https://doi.org/10.1080/00224499. 2021.1875188

Mikolajczyk, R. T., Akmatov, M. K., Stich, H., Krämer, A., \& Kretzschmar, M. (2008). Association between acculturation and childhood vaccination coverage in migrant populations: A population based study from a rural region in Bavaria, Germany. International Journal of Public Health, 53(4), 180-187. https://doi.org/ 10.1007/s00038-008-8002-4

Norredam, M., Nielsen, S. S., \& Krasnik, A. (2010). Migrants' utilization of somatic healthcare services in Europe - A systematic review. European Journal of Public Health, 20(5), 555-563. https://doi.org/10.1093/eurpub/ckp195

Rade, D. A., Crawford, G., Lobo, R., Gray, C., \& Brown, G. (2018). Sexual health help-seeking behavior among migrants from Sub-Saharan Africa and South East Asia living in high income countries: A systematic review. International Journal of Environmental Research and Public Health, 15(7), 1311. https://doi. org/10.3390/ijerph15071311

Rao, J. N., \& Scott, A. J. (1981). The analysis of categorical data from complex sample surveys: Chi-squared tests for goodness of fit and independence in two-way tables. Journal of the American Statistical Association, 76(374), 221-230.

Rechel, B., Mladovsky, P., Ingleby, D., Mackenbach, J. P., \& McKee, M. (2013). Migration and health in an increasingly diverse Europe. The Lancet, 381(9873), 1235-1245. https://doi.org/ 10.1016/S0140-6736(12)62086-8

Remschmidt, C., Fesenfeld, M., Kaufmann, A. M., \& Deleré, Y. (2014). Sexual behavior and factors associated with young age at first intercourse and HPV vaccine uptake among young women in Germany: Implications for HPV vaccination policies. BMC Public Health, 14, 1248. https://doi.org/10.1186/ 1471-2458-14-1248

Robert Koch-Institut. (2007). Impfempfehlungen der STIKO. Epidemiologisches Bulletin 30. Retrieved from: https://www.rki.de/ DE/Content/Infekt/EpidBull/Archiv/2007/Ausgabenlinks/30_ 07.pdf?_blob=publicationFile

Rivera, B., Casal, B., \& Currais, L. (2015). Length of stay and mental health of the immigrant population in Spain: Evidence of the healthy immigrant effect. Applied Economics, 47(19), 1972-1982.

Rommel, A., Saß, A. C., Born, S., \& Ellert, U. (2015). Die gesundheitliche Lage von Menschen mit Migrationshintergrund und die Bedeutung des sozioökonomischen Status : Erste Ergebnisse der Studie zur Gesundheit Erwachsener in Deutschland (DEGS1) [Health status of people with a migrant background and impact of socio-economic factors: First results of the German Health Interview and Examination Survey for Adults (DEGS1)]. Bundesgesundheitsblatt, Gesundheitsforschung, Gesundheitsschutz, 58(6), 543-552. https://doi.org/10.1007/s00103-015-2145-2

Sadry, S. A., De Souza, L. R., \& Yudin, M. H. (2013). The impact of ethnicity on awareness and knowledge of and attitudes towards the human papillomavirus and vaccine among adult women. Journal of Obstetrics and Gynaecology Canada, 35(11), 995-1003. https://doi.org/10.1016/S1701-2163(15)30787-8

Sarría-Santamera, A., Hijas-Gómez, A. I., Carmona, R., \& GimenoFeliú, L. A. (2016). A systematic review of the use of health services by immigrants and native populations. Public Health Reviews, 37, 28. https://doi.org/10.1186/s40985-016-0042-3

Statistisches Bundesamt. (2018). Fachserie 1 Reihe 2.2. Bevölkerung und Erwerbstätigkeit. Bevölkerung mit Migrationshintergrund - Ergebnisse des Mikrozensus 2017. Retrieved from: https://www.destatis.de/DE/ Themen/Gesellschaft-Umwelt/Bevoelkerung/Migration-Integration/ Publikationen/Downloads-Migration/migrationshintergrund2010220177004.pdf?_blob=publicationFile \&v $=4$

Statistisches Bundesamt. (2020). Bevökerung nach Migrationshintergrund und Geschlecht. Retrieved from: https://www.destatis.de/DE/ Themen/Gesellschaft-Umwelt/Bevoelkerung/Migration-Integration/ Tabellen/liste-migrationshintergrund-geschlecht.html

Uiters, E., Devillé, W., Foets, M., Spreeuwenberg, P., \& Groenewegen, P. P. (2009). Differences between immigrant and non-immigrant groups in the use of primary medical care; a systematic review. BMC Health Services Research, 9, 76. https://doi.org/10.1186/ 1472-6963-9-76

United Nations. (2020a). World migration report. Retrieved from: https://www.un.org/sites/un2.un.org/files/wmr_2020.pdf

United Nations. (2020b). World family planning. Retrieved from: https://www.un.org/development/desa/pd/sites/www.un.org. 
development.desa.pd/files/files/documents/2020/Sep/unpd_ 2020_worldfamilyplanning_highlights.pdf

von Rosen, F. T., von Rosen, A. J., Müller-Riemenschneider, F., Damberg, I., \& Tinnemann, P. (2018). STI knowledge in Berlin adolescents. International Journal of Environmental Research and Public Health, 15(1), 110. https://doi.org/10.3390/ijerph15010110

Wiessner, C., Keil, T., Krist, L., Zeeb, H., Dragano, N., Schmidt, B., Ahrens, W., Berger, K., Castell, S., Fricke, J., Führer, A., Gastell, S., Greiser, H., Guo, F., Jaeschke, L., Jochem, C., Jöckel, K. H., Kaaks, R., Koch-Gallenkamp, L., ... Becher, H. (2020). Personen mit Migrationshintergrund in der NAKO Gesundheitsstudie soziodemografische Merkmale und Vergleiche mit der autochthonen deutschen Bevölkerung [Persons with migration background in the German National Cohort (NAKO)-sociodemographic characteristics and comparisons with the German autochthonous population]. Bundesgesundheitsblatt, Gesundheitsforschung, Gesundheitsschutz, 63(3), 279-289. https://doi.org/10.1007/s00103-020-03097-9

Publisher's Note Springer Nature remains neutral with regard to jurisdictional claims in published maps and institutional affiliations. 